\title{
Development of a Prognostic Factor Prediction Model in Patients with Musculoskeletal Pain Treated with Homeopathy: An Individual Patient Data Meta-Analysis of Three Randomized Clinical Trials
}

\author{
Robbert van Haselen \\ International Institute for Integrated Medicine, Kingston, UK
}

\author{
Keywords \\ Prognostic factor research · Individual patient \\ data meta-analysis - Treatment individualization . \\ Spiroflor SRL ${ }^{\circledR}$ gel
}

\begin{abstract}
Background: Prognostic factor research methodology has not yet been applied to randomized clinical trial data of homeopathic medicines. Objectives: To investigate the principle of individualization in homeopathy by developing a prognostic factor prediction model. Method: A pooled, individual patient data meta-analysis of 3 randomized trials investigating the efficacy of a homeopathic gel (Spiroflor $\mathrm{SRL}^{\circledR}$ ) containing Rhus toxicodendron as a key ingredient in osteoarthritis of the knee and acute low back pain. The prognostic value of a predefined set of 5 typical $R$. toxicodendron symptoms was investigated by assessing treatment-bysymptom interactions on pain as an outcome measure in a regression model. Results: The pooled dataset consisted of 284 patients in the Spiroflor SRL group and 275 patients in the control group. Adjusted for pain at baseline, a statistically significant effect modification for the symptoms "numbness or tingling of the affected part" (+2.0 mm VAS; $p=0.02)$, "amelioration by movement" (-5.6 mm VAS; $p=$ 0.01 ), and "amelioration of pain by local heat" (+7.0 mm VAS; $p=0.02$ ) was found. Conclusions: Investigating aspects of treatment individualization in homeopathy using random-
\end{abstract}

karger@karger.com www.karger.com/cmr

Karger $\%$

GOPEN ACCESS (c) 2020 The Author(s)

Published by S. Karger AG, Basel

This is an Open Access article licensed under the Creative Commons Attribution-NonCommercial-4.0 International License (CC BY-NC) (http://www.karger.com/Services/OpenAccessLicense), applicable to the online version of the article only. Usage and distribution for con- ized trial data and standard meta-analytical techniques is possible. The symptom amelioration by local heat is of possible value as a homeopathic symptom (prognostic factor) predicting an increased likelihood of pain relief following treatment with the homeopathic product.

\section{The Author(s)}

Published by S. Karger AG, Basel

\section{Introduction}

The main consequences of having a musculoskeletal condition are disability and pain. Osteoarthritis and unexplained back pain are among the commonest musculoskeletal consultations. Musculoskeletal conditions place a significant burden on individual patients as well as on society (costs). The impact of musculoskeletal diseases is set to increase in developed countries with an ageing population and high life expectancy $[1,2]$.

Homeopathy is a complementary and alternative medicine (CAM) modality where specific symptoms of the patient are of particular importance in the process of identifying the correct treatment. Individualization of treatment is based on symptoms derived from homeopathic pathogenic trials ("provings") [3] as well as validation of homeopathic signs and symptoms in clinical practice [4]. The homeopathic "materia medica" and "repertories" provide a rich source of information on which to base individualized prescribing. However, it is also clear that there is a need for 
further validation of these symptoms as predictors of intended treatment effects in patients. Homeopathic theory states that, the better the "match" between the homeopathic "drug picture" and the patient's symptoms, the better the treatment result will be [5]. Patients whose symptoms do not match the symptoms associated with the prescribed homeopathic medicine are less likely to display intended treatment effects. To study treatment individualization in homeopathy, a spectrum of methods can be employed, ranging from qualitative methodology $[6,7]$ to elicit the "patterns" in homeopathic remedy pictures to quantitative research methods. Early attempts to establish a theoretical framework for the link between quantitative epidemiological methods and treatment individualization in homeopathy were made by van Haselen $[8,9]$.

Likelihood ratios have long been used for diagnostic purposes in medicine [10], and Stolper et al. [11] demonstrated that the "likelihood ratio" can also be applied to verify the diagnostic value of homeopathic symptoms. Rutten [12-16] argued that in homeopathy the diagnostic indicators (signs and symptoms) used for the selection of individualized homeopathic medicine are in fact "prognostic factors" for predicting treatment success with that particular homeopathic medicine. He has initiated a prognostic factor research program that has been gaining further momentum in the homeopathic community during the last decade [12-16]. This program confirmed that the rapidly developing epidemiological field of prognostic research $[17,18]$ can be applied to homeopathy.

This paper is an extension of the earlier theoretical work by van Haselen $[8,9]$ and focuses on exploring the role of clinical trials in further validating the prognostic value of selected homeopathic symptoms (prognostic factors) of a particular homeopathic medicine as predictors of treatment success. Assessing the role of individual patient characteristics in predicting which individuals are most likely to benefit is called "meta-regression" [19]. The gold standard meta-regression approach is considered to be the meta-analysis of individual patient data (IPD) from multiple clinical trials [20]. Meta-analysis of IPD from experimental research is a potentially interesting solution for the causality problem associated with prognostic factor research based on observational data.

Spiroflor SRL ${ }^{\circledR}$ gel is a homeopathic medicinal product marketed for musculoskeletal pain since 1974 in The Netherlands as well as many other European countries (including Germany under the name DHU Rhus comp. $\mathrm{Gel}^{\circledR}$ ) and the USA (under the name Triflora ${ }^{\circledR}$ Arthritis Gel). It contains the following 3 plant-based homeopathic ingredients: symphytum ad usum externum, Rhus toxicodendron (commonly known as "poison ivy"), and $L e$ dum. Three randomized trials investigated the effect of SRL gel in patients with musculoskeletal pain. In each trial, the presence or absence of $5 R$. toxicodendron symp- toms was assessed at baseline. The present study further investigates the predictive value of these 5 symptoms in the treatment of musculoskeletal pain by analyzing [19, $21,22]$ the (pooled) IPD of the above-mentioned trials. This is the first homeopathic prognostic factor research study based on an IPD meta-analysis.

The primary aim of this study is to develop a prognostic factor prediction model for musculoskeletal pain in patients treated with a homeopathic medicinal product. A secondary objective is to explore the feasibility of such an approach for homeopathy and other CAM modalities with strong roots in treatment individualization.

This paper complies with the TRIPOD guideline for the reporting of multivariable prediction models for individual treatment prognosis [23].

\section{Materials and Methods}

\section{Design and Setting}

The 3 studies were all randomized controlled trials [24-26]. In brief, the first (mono-center) trial (study 1) involved a randomized comparison of SRL gel versus piroxicam gel in 184 patients with osteoarthritis of the knee and took place at the Department of Rheumatology of St. Bartholomew's Hospital, London, UK, between 1993 and 1995 [26]. The second (multicenter) trial (study 2) compared SRL gel with a placebo gel in 214 patients, also with osteoarthritis of the knee, and took place in rheumatologic outpatient clinics in Holland and Belgium from 1995 to 1997 [24]. The third (multicentre) trial (study 3 ) investigated the effect of SRL gel versus Cremor Capsici Compositus FNA in 161 patients with acute low back pain and took place in 19 general practices in the UK from 1994 to 1996 [25]. The aim of studies 1 and 3 was to show therapeutic equivalence. While in all 3 studies the medicine containers (tubes) were masked, it was not possible to achieve full double blinding due to differences between the characteristics of SRL gel and the control treatments.

\section{Outcome}

The primary outcome of each trial and therefore of the present analysis was the magnitude of pain after treatment, assessed in each patient using a visual analogue score (VAS) ranging from 0 (no pain) to $100 \mathrm{~mm}$ (maximal pain) [27].

\section{R. toxicodendron Symptoms Investigated}

The presence or absence of the following 5 symptoms considered to be important ("keynote") criteria for the selection of the homeopathic medicine R. toxicodendron [28] (referred to as Rhustox) was documented by the investigator at baseline as follows:

Are the complaints ameliorated by movement/moving?

Are the complaints worse during cold, wet weather?

Does the patient - occasionally - experience numbness and/or tingling?

Does the patient have rapid (within $30 \mathrm{~min}$ ) stiffening after sitting and/or lying?

Are the complaints ameliorated by local heat?

\section{Analysis}

The primary aim of the analysis was to quantify whether the effect of SRL treatment in patients with 1 or more of the selected Rhus-tox symptoms was different from the effect in patients with 
Table 1. Distribution of the baseline characteristics across the treatment groups per trial separately and in the combined dataset

\begin{tabular}{|c|c|c|c|c|c|c|c|c|}
\hline \multirow[t]{2}{*}{ Characteristic } & \multicolumn{2}{|l|}{ Study 1} & \multicolumn{2}{|l|}{ Study 2} & \multicolumn{2}{|l|}{ Study 3} & \multicolumn{2}{|l|}{ Combined } \\
\hline & SRL & piroxicam & SRL & placebo & SRL & CCC & SRL & control \\
\hline Patients, $n$ & 92 & 92 & 109 & 105 & 83 & 78 & 284 & 275 \\
\hline Age, years & $65.3 \pm 8.8$ & $63.1 \pm 9.5$ & $66.1 \pm 9.4$ & $66.9 \pm 8.7$ & $40.66 \pm 13.5$ & $41.04 \pm 12.8$ & $58.4 \pm 15.6$ & $58.3 \pm 15.0$ \\
\hline Sex (males:females) & $23: 77$ & 29:71 & $16: 84$ & $11: 89$ & $55: 45$ & $53: 47$ & $30: 70$ & 29:71 \\
\hline Weight, kg & $80.7 \pm 16.2$ & $79.9 \pm 16.2$ & $75.6 \pm 13.6$ & $76.4 \pm 14.9$ & $70.1 \pm 12.9$ & $76.0 \pm 14.3$ & $75.7 \pm 14.9$ & $77.4 \pm 15.2$ \\
\hline Comorbidity (yes:no) & $66: 34$ & $58: 42$ & $77: 23$ & $90: 10$ & $42: 58$ & $51: 49$ & $63: 37$ & $68: 32$ \\
\hline NSAID use (yes:no) & $44: 56$ & $40: 60$ & $3: 97$ & $4: 96$ & $17: 83$ & $28: 72$ & $20: 80$ & $23: 77$ \\
\hline Analgesic use (yes:no) & $22: 78$ & $22: 78$ & $73: 27$ & $74: 26$ & 49:51 & 45:55 & 49:51 & 48:52 \\
\hline Worsened by cold (yes:no) & $63: 37$ & $63: 37$ & $68: 32$ & $69: 31$ & $39: 61$ & $40: 60$ & $58: 42$ & $59: 41$ \\
\hline Numbness/tingling (yes:no) & $26: 74$ & $28: 72$ & $26: 74$ & $24: 76$ & $30: 70$ & $32: 68$ & $27: 73$ & $28: 72$ \\
\hline Rapid stiffening (yes:no) & $90: 10$ & 89:11 & $77: 23$ & $87: 13$ & $74: 26$ & $82: 18$ & $80: 20$ & $86: 14$ \\
\hline Ameliorated by movement (yes:no) & $66: 34$ & $65: 35$ & 58:42 & 59:41 & 68:32 & 64:36 & 63:37 & $63: 37$ \\
\hline Ameliorated by heat (yes:no) & 61:39 & $60: 40$ & $46: 54$ & $50: 50$ & 100:0 & 100:0 & $72: 28$ & $75: 25$ \\
\hline Pain at baseline, mm VAS & $59.8 \pm 21.8$ & $56.4 \pm 20.7$ & $56.9 \pm 17.1$ & $54.1 \pm 17.1$ & $58.9 \pm 20.8$ & $55.5 \pm 22.7$ & $58.5 \pm 19.8$ & $55.4 \pm 19.9$ \\
\hline
\end{tabular}

Values are percentages or means \pm SD. Percentages have been rounded to the nearest whole number.

the same Rhus-tox symptoms receiving the (nonhomeopathic) control treatment. For this, we tested whether there was a significant statistical interaction between the Rhus-tox symptom(s) and the treatment received (either SRL or control treatment) with regard to change in VAS score at follow-up. If such an interaction was absent, treatment effects were similar regardless of the presence or absence of these symptoms. A significant $(p<0.05)$ interaction indicates that the presence of the particular symptom modifies/influences the treatment effect.

It was first assessed whether there were any baseline differences in the pooled data set between the (pooled) SRL treatment group and the (pooled) control group. Since the clinical indications and settings differed, heterogeneity across the 3 study populations was assessed. To address possible heterogeneity, a random effects linear regression model in the pooled dataset was used. The mean VAS score (in patients with different Rhus-tox symptoms) was calculated, accounting for any differences between the 3 data sets. The random effects models utilized always corrected for VAS at baseline [29]. Hence, a model looks like this: VAS score at follow-up = $\mathrm{a}+\mathrm{b} 1 \times$ treatment $+\mathrm{b} 2 \times$ Rhus-tox symptom $+\mathrm{b} 3 \times$ (treatment $\times$ Rhus-tox symptom) $+\mathrm{b} 4 \times$ pain at baseline.

Treatment was either 1 (SRL) or 0 (control treatment), the Rhus-tox symptom was either 1 (present) or 0 (absent), and pain at baseline was included as a continuous variable (mm VAS). $\alpha$, also referred to as the "intercept," represents the VAS score at follow-up in the control group (treatment $=0$ ) in the absence of all the Rhus-tox symptoms (Rhus-tox symptoms have a value 0 , so all the terms that include "Rhus-tox symptom" become 0 ). The term "b2" represents the influence of that symptom as an independent factor on pain reduction. The term "b3" is the "treatment by symptom interaction term" and represents whether the treatment effect (difference in VAS score at follow-up between SRL and the control) is modified by the presence of the symptom. If the treatment effect is the same in the subgroups with and without the symptom, the term b3 becomes 0 (no effect modification by the symptom). If the treatment effect is different in the subgroup with the symptom compared to the subgroup without the symptom, there is an effect modification and the term b3 directly represents this difference (in mm VAS). The term b4 represents, and adjusts for, the influence of the pain at baseline on the pain at follow-up. So if the "treatment-by-symptom" interaction term b3 was not 0 and its
95\% CI excluded 0, the difference in treatment effect (SRL - CT) was considered to be modified by the presence of the symptom. In other words, b3 reflects the difference in treatment effect between the subgroups with and without the symptom of interest, adjusted for pain at baseline. This model was fitted for each of the 5 a priori defined Rhus-tox symptoms. The 95\% CI (and $p$ values) were adjusted for multiple testing (using the Bonferroni correction method) even though the 5 interactions under study were defined a priori.

For exploratory purposes, we also investigated "higher-order" interactions. For instance, if the presence of one symptom modified a pain reduction of $3 \mathrm{~mm}$ in the SRL group as compared to the control group, and the same applied to another symptom, the presence of both symptoms could yield significantly less ("antagonism") or more ("synergism") than $6 \mathrm{~mm}$ pain reduction (2ndorder interaction). In classical (individualized) homeopathy with single medicines, such higher-order interactions are considered to be important because effects are claimed to be superior when a particular "pattern" of symptoms is present that "matches" the remedy picture [5]

Some patients had missing values for one or more variables. Missing values ranged from $1.8 \%$ in "rapid stiffening of the affected part" to $24.2 \%$ in "amelioration by heat." VAS scores at follow-up were missing in $6.3 \%$ of patients. Missing data were (single) imputed using a regression approach (with addition of a random error component) and S-PLUS (professional edition, version 6.2) before conducting the analyses. SAS for Windows (version 8) was used for the remaining analyses.

\section{Results}

The baseline characteristics of the 3 study populations are given in Table 1, which shows that there were no major differences between the treatment groups per trial or in the pooled data set, except for slight differences in the pooled data set for comorbidity, stiffening, pain ameliorated by heat, and baseline VAS score. The latter further 
Table 2. Analyses of the VAS scores at follow-up in the combined (pooled) dataset in relation to the 5 symptoms and SRL treatment

\begin{tabular}{|c|c|c|c|c|c|c|c|c|c|}
\hline Symptom & $\begin{array}{l}\text { Symptom } \\
\text { Presence }\end{array}$ & Treatment & $\begin{array}{l}\text { Estimated } \\
\text { mean VAS } \\
\text { at follow-up }\end{array}$ & $\begin{array}{l}\text { Difference in mean VAS } \\
\text { at follow-up as compared } \\
\text { to the reference group }\end{array}$ & $\begin{array}{l}\text { Adjusted }{ }^{c} 95 \% \text { CI for } \\
\text { difference in mean VAS } \\
\text { at follow-up }\end{array}$ & $\begin{array}{l}\text { Treatment } \\
\text { effect }^{\mathrm{b}}\end{array}$ & $\begin{array}{l}\text { Adjusted } \\
95 \% \text { CI for } \\
\text { treatment } \\
\text { effect }\end{array}$ & $\begin{array}{l}\text { Effect modification } \\
\text { by the symptom } \\
\text { (mm VAS) }\end{array}$ & $\begin{array}{l}95 \% \mathrm{CI} \\
\text { for effect } \\
\text { modification }\end{array}$ \\
\hline \multirow{5}{*}{$\begin{array}{l}\text { Worsening of pain } \\
\text { in cold wet weather }\end{array}$} & Yes & SRL & 39.8 & 2.2 & -6.4 to 10.8 & & & \multirow{5}{*}{3.4} & \multirow{5}{*}{-4.4 to 11.4} \\
\hline & Yes & Reference & 42.9 & 5.3 & -3.1 to 13.7 & 3.1 & 0.5 to 5.8 & & \\
\hline & $\mathrm{No}$ & SRL & 37.9 & 0.3 & -8.1 to 8.7 & & & & \\
\hline & & & & & & -0.3 & -8.8 to 8.0 & & \\
\hline & No & Reference & 37.6 & - & & & & & \\
\hline \multirow{6}{*}{$\begin{array}{l}\text { Numbness or } \\
\text { tingling of the } \\
\text { knee or lower back }\end{array}$} & Yes & SRL & 37.8 & -2.5 & -6.5 to 1.5 & & & \multirow{6}{*}{2.0} & \multirow{6}{*}{0.3 to 3.7} \\
\hline & & & & & & 2.4 & -0.5 to 5.3 & & \\
\hline & Yes & Reference & 40.2 & -0.1 & -3.2 to 3.0 & & & & \\
\hline & No & SRL & 39.9 & -0.4 & -5.3 to 4.5 & & & & \\
\hline & & & & & & 0.4 & -4.5 to 5.3 & & \\
\hline & No & Reference & 40.3 & - & & & & & \\
\hline \multirow{6}{*}{$\begin{array}{l}\text { Rapid stiffening } \\
\text { of the knee or } \\
\text { lower back }\end{array}$} & Yes & SRL & 38.3 & -2.1 & -6.8 to 2.6 & & & \multirow{6}{*}{0.8} & \multirow{6}{*}{-1.5 to 3.1} \\
\hline & & & & & & 1.8 & -2.0 to 5.6 & & \\
\hline & Yes & Reference & 40.1 & -0.3 & -1.1 to 0.5 & & & & \\
\hline & No & SRL & 39.4 & -1.0 & -5.3 to 3.3 & & & & \\
\hline & & & & & & 1.0 & -3.5 to 5.5 & & \\
\hline & No & Reference & 40.4 & - & & & & & \\
\hline \multirow{6}{*}{$\begin{array}{l}\text { Amelioration } \\
\text { of pain by } \\
\text { movement }\end{array}$} & Yes & SRL & 38.7 & -4.5 & -10.4 to 1.4 & & & \multirow{6}{*}{-5.6} & \multirow{6}{*}{-9.6 to -1.5} \\
\hline & & & & & & -1.4 & -6.4 to 3.6 & & \\
\hline & Yes & Reference & 37.3 & -5.9 & -9.2 to -2.6 & & & & \\
\hline & No & SRL & 39.0 & -4.2 & -8.4 to 0.0 & & & & \\
\hline & & & & & & 4.2 & 0.0 to 8.4 & & \\
\hline & No & Reference & 43.2 & - & & & & & \\
\hline \multirow{6}{*}{$\begin{array}{l}\text { Amelioration } \\
\text { of pain by } \\
\text { local heat }\end{array}$} & Yes & SRL & 33.9 & -7.8 & -12.9 to -2.7 & & & \multirow{6}{*}{7.0} & \multirow{6}{*}{1.0 to 13.0} \\
\hline & & & & & & 4.9 & -2.5 to 12.3 & & \\
\hline & Yes & Reference & 38.8 & -2.9 & -12.0 to 6.2 & & & & \\
\hline & No & SRL & 43.8 & 2.1 & 0.3 to 2.9 & & & & \\
\hline & & & & & & -2.1 & -3.9 to -0.3 & & \\
\hline & No & Reference & 41.7 & - & & & & & \\
\hline
\end{tabular}

a Adjusted for VAS at baseline; reported mean VAS scores are not the means actually observed in the studies but rather the means predicted by the random effects model, which takes into account any heterogeneity between the studies; the reference group was always defined as those patients without the symptom on reference treatment. ${ }^{b}$ Defined as the mean VAS at follow-up in the reference group minus the mean VAS at follow-up in the SRL group in patients with the symptom of interest and in patients without the symptom of interest; a positive sign of the treatment effect indicates less pain at follow up in the SRL group. ${ }^{c}$ Bonferroni adjusted, based on 3 comparisons, i.e., $95 \% \mathrm{CI}$ defined by the mean $\pm 2.40 \times$ standard error of the mean difference. $95 \% \mathrm{CI}$ that exclude the value 0 are statistically significant.

underscored the need for permanent adjustment in the analysis for VAS at baseline.

Loss to follow-up for the main outcome measure was limited in each trial, i.e., in study 1 , five (3 SRL and 2 CT) of the 184 patients; in study 2, eight (3 SRL and 5 CT) of the 214 patients; and in study 3 , six (2 SRL and 4 CT) of the 161 patients. For the 3 populations combined, loss to follow-up was $3.5 \%$ on average.

With regard to the 5 Rhus-tox symptoms, rapid stiffening seemed of limited value in the context of identifying predictors of a positive treatment response because over $80 \%$ of all patients had this symptom (it is a primary clinical feature associated with osteoarthritis).

Table 2 shows the results of the random effects linear regression models. Per Rhus-tox symptom and type of treatment, the mean VAS score at follow-up as well as the difference in mean VAS score as compared to the reference group (i.e., patients with an absence of the symptom and receiving the reference treatment) is given. To enhance comprehension of this table, the data from the first listed Rhus-tox symptom, i.e., pain worse during cold weather, is depicted in Figure 1.

Figure 1 shows that, in patients in whom the symptom was absent, the mean baseline adjusted VAS score at follow-up was almost the same in the SRL as in the reference group (0.3-mm difference). In patients in whom this symptom was present, the between-treatment difference was $3.1 \mathrm{~mm}$ in favor of the SRL group, which can also be read from Table 2 . The nonparallel lines indicate the presence of an interaction between the treatment and the symptom, i.e., the SRL treatment effect was modified by the presence or absence of the symptom. The stronger the interaction, the more the lines will be nonparallel. The extent of the effect modification was determined by the difference in the between-treatment effects across the 2 subgroups - with and without the symptom - which in the above example was $3.4 \mathrm{~mm}(3.1-[-0.3])$.

Table 2 shows that the estimated effect modification by the symptom numbness or tingling of the affected part was $2.0 \mathrm{~mm}(2.4-0.4)$. For rapid stiffening the effect 
Fig. 1. Graphical depiction of the betweentreatment difference in mean VAS at follow-up (adjusted for baseline VAS) in patients with and without the symptom "worse in cold wet weather."

Fig. 2. Graphical depiction of the between treatment difference in mean VAS at follow-up (adjusted for baseline VAS) in patients with and without the symptom "amelioration by local heat."
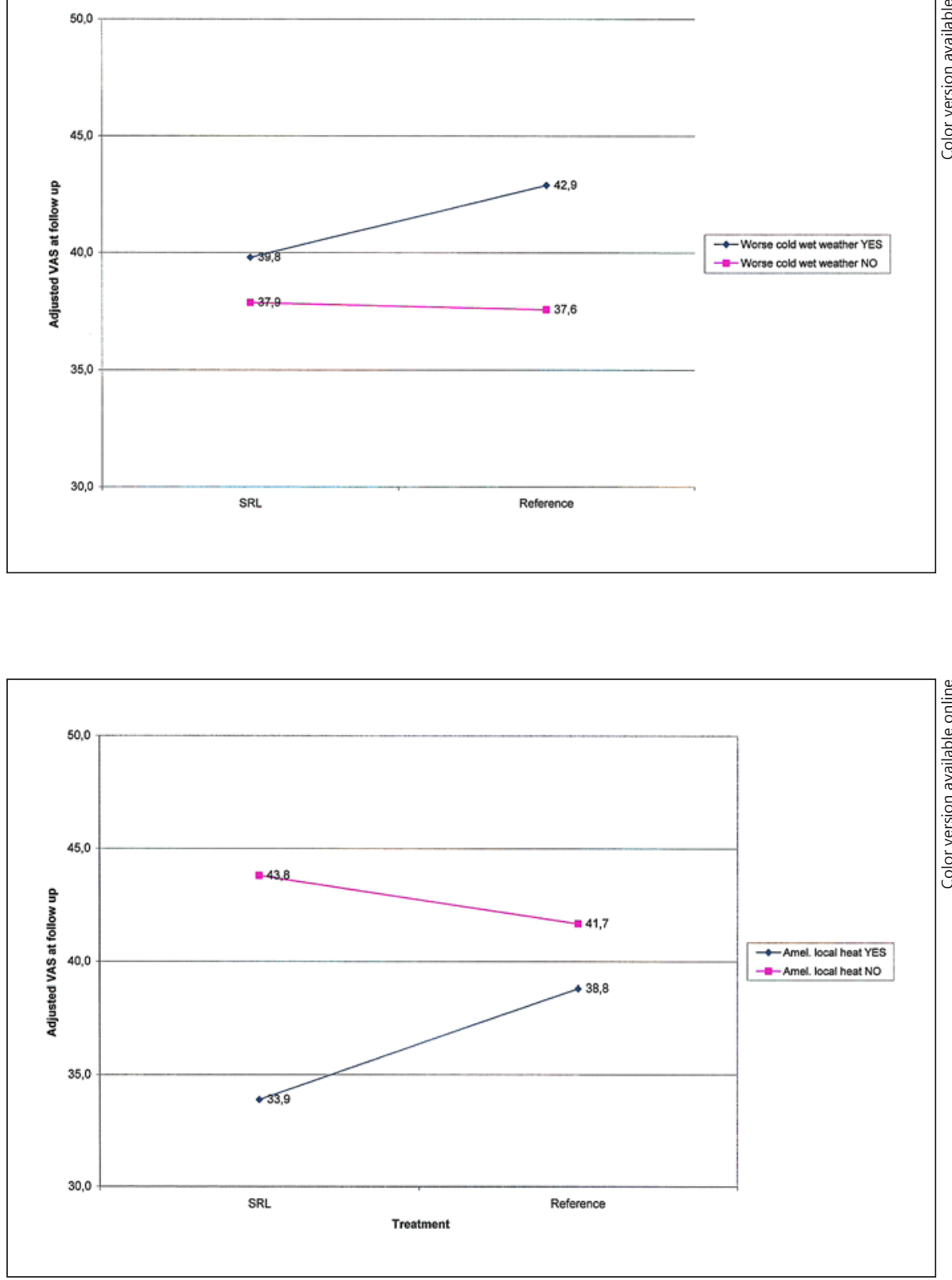

modification was $0.8 \mathrm{~mm}(1.8-1.0)$, and for amelioration by movement it was $-5.6 \mathrm{~mm}(-1.4-4.2)$. The negative sign of the latter difference indicates a larger effect for SRL in the absence of the symptom. The largest effect modification was for amelioration of pain by local heat, i.e., $7.0 \mathrm{~mm}(4.9-[-2.1])$, which is also depicted in Figure 2.

The 95\% CI of the different effect modifications are given in the last column of Table 2. The treatment-bysymptom interactions (effect modifications) that reached statistical significance $(p<0.05)$ were numbness or tingling of the affected part $(p=0.02)$, amelioration by movement $(p=0.01)$, and amelioration of pain by local heat $(p=0.02)$. Note that despite a larger size of the effect modification for pain worse during cold weather compared to, for instance, numbness or tingling of the affected part, the effect modification by pain worse during cold weather was not statistically significant. This is explained by a much larger SD in the VAS at follow-up in the subset of patients with this symptom, leading to a much wider - non-statistically significant - 95\% CI.

\section{Further Exploratory Analyses}

We conducted a number of further exploratory analyses, including the modelling of various combinations of symptoms (including having all 5 symptoms). We were 
unable to identify significant interactions associated with particular combinations of symptoms (data not shown). We also explored the presence of higher-order interactions in the dataset, but none of these analyses indicated strong tendencies in the data. Therefore, there did not appear to be synergistic effects of combining more than 2 symptoms.

\section{Discussion/Conclusion}

This is one of the first studies to illustrate that it is possible to quantitatively investigate aspects of treatment individualization alongside carefully designed and executed randomized trials.

In this study, effect modification by some of the homeopathic symptoms did occur. The largest (significant) effect was found for amelioration by local heat, though it was still small. Higher-order interactions were not significant, which suggests that there were no "patterns" of 2 or more of the 5 chosen symptoms which, if present, significantly modified the treatment outcome.

To appreciate these findings, a few issues need to be discussed. The findings may be - as always in these types of (multiple subgroup) analyses - attributed to a type 1 error, i.e., claiming there is an effect while in reality there is none. To address this potential criticism, an individual patient data analysis of 3 randomized trials was conducted to enhance the power of the planned analyses. Furthermore, the 5 symptom subgroups were predefined and all other analyses (which were nonsignificant anyhow) were considered to be exploratory. Moreover, the relatively conservative Bonferroni adjustment for multiple testing was applied.

The 3 pooled trials used different control - either standard medical or placebo - treatments. However, this is unlikely to have hampered the present analyses and inferences. The aim of this analysis was not to compare the overall effect of SRL treatment as compared to the reference treatment. Rather, it was to assess whether the Spiroflor SRL treatment effect was modified by the presence of the homeopathic Rhus-tox symptoms (in other words, to assess whether the homeopathic symptoms are prognostic factors, predicting an increased effect in favor of SRL treatment).

In this analysis a relatively heterogeneous diagnostic population was used, which included both osteoarthritis and acute low back pain. It should be noted that in homeopathy the symptoms of the patient, rather than the clinical diagnosis, determines the choice of the medicine. This means that one homeopathic medicine can be used for more than one clinical diagnosis. Pooling patients with more than one - conventional - clinical diagnosis was therefore not a problem.
A significant strength of the chosen approach is the use of random treatment allocation, which adjusts for possible "confounding by indication" [30].

Another important aspect is the clinical relevance of the observed subgroup effects. For this it should be considered what is a minimal clinically relevant difference in terms of pain relief or rather to distinguish a minimal clinically important change and a minimal detectable change. This is a complex subject matter on which there is no general consensus. Since the aim was to investigate the possible contribution of individual homeopathic symptoms to the overall SRL treatment effect, it was considered to be more appropriate to focus on the minimal clinically detectable change perceived by patients. Intraindividual (paired) comparison studies suggest that within a short time frame differences of about $5 \mathrm{~mm}$ VAS are detectable [31]. The observed modifications by amelioration by local heat and by the absence of amelioration by movement are therefore clinically detectable.

From a clinical perspective, further investigation (in larger samples with a wider range of symptoms) is required into the extent to which the combination of particular individual homeopathic symptoms further increases the effectiveness of SRL on pain. The absence of enhanced effects of combinations of symptoms in our exploratory analyses could have been partly due to the unexpected finding that the symptom amelioration by movement modified the effect in a negative direction for SRL, so the possible effect of a combination of the symptoms as recorded in this study could have been cancelled out by the inclusion of amelioration by movement. One possible way of dealing with this is to consider absence of amelioration by movement as a prognostic factor. However, the absence of a symptom is rarely used as a remedy selection criterion, and it is applicable principally when the absence of a particular symptom is clinically unexpected - for instance, the unexpected absence of pain in a patient as a selection criterion for opium. A better alternative is to approach "movement" as a "polar symptom," which is defined as a symptom that encompasses the opposites [32] of an amelioration or aggravation by movement. It is conceivable that the absence of amelioration by movement was actually indicative of an aggravation by movement (even though this was not explicitly asked). "Aggravation by movement" is listed in the homeopathic repertory as a selection criterion for Ledum, which is one of the other ingredients of SRL. It is therefore possible that some patients responded to the ingredient Rhus-tox and others to the ingredient Ledum and that the latter improved patients with the symptom aggravation by movement. From a clinical perspective, both aggravation and amelioration by movement are symptoms commonly experienced by patients with osteoarthritis. Therefore, addressing both these symptoms would be consistent with the postulation 
that the symptom pictures of the ingredients of homeopathic combination products should cover all the symptoms commonly experienced by patients with the target indication [33]. Unfortunately, the symptom "movement, aggravates," was not recorded separately, nor was the intensity of the symptom graded. At any case, this finding underlines the importance of recording the polarity of symptoms - where appropriate - in future studies.

A possible weakness of this study is the selection of only a limited set of 5 symptoms. However, the same symptoms were used successfully in a previous fibromyalgia trial [28]. A valid criticism from a homeopathic perspective is that keynote symptoms should have been selected in accordance with paragraph 153 of the Organon, written by the founder of homeopathy, S. Hahnemann [5]. He stated that the "more striking, singular, uncommon and peculiar" signs and symptoms of the case should preferentially be taken into consideration. For instance, a typical (but less common) Rhus-tox symptom is a "desire for milk." In this study, the symptom rapid stiffening was not an effect modifier, and this is perhaps unsurprising because it is a pathophysiological symptom associated with osteoarthritis. The 3 other symptoms were in fact symptom modalities (for instance amelioration by local heat) that are relatively common in patients with musculoskeletal conditions, but without a direct pathophysiological connection. Even though it is not a highly characteristic modality, it was encouraging to see that a symptom such as amelioration by local heat was associated with a clinically relevant effect modification. It is clear that for the study of effect modification by more characteristic - but less common - homeopathic symptoms, very large clinical trial populations would be needed.

The investigational medication - SRL gel - was topically applied and contained Rhus-tox in combination with other homeopathic ingredients. Although the external application of homeopathic medicinal products, specifically for the treatment of injuries and localized musculoskeletal pain, is justified $[34,35]$, it cannot be assumed that the "systemic" effects of a topically applied homeopathic product are identical to the effects of the same product taken orally. Also, the homeopathic drug picture of a combination remedy is not necessarily the same as the homeopathic drug picture of one of its ingredients taken as a single substance. Therefore, the inability to identify higher order interactions (synergistic effects when 2 or more symptoms are present in a particular combination) does not reflect on classical (single medicine) homeopathy. In this study we merely aimed to demonstrate that the "homeopathic" value of particular (combinations of) symptoms can indeed be studied quantitatively using modern prognostic factor research methods. The latter is of course subject to the condition of sufficient statistical power. The number of symptom combinations that can be studied is likely to be fairly quickly limited by the number of patients available in pooled datasets. For practical reasons, this approach will therefore always be "reductionist" when compared with the full, and virtually unlimited, range of symptoms that can be utilized in classical homeopathic treatment. The chosen model can still be useful in situations where the selection of patients is based on a limited set of typical, highly individualizing, symptoms (often called keynote symptoms) [36-39].

The literature was searched to see if other IPD metaanalyses have been utilized in the CAM field. While this was the case for some other CAM treatments, such as for instance glucosamine in osteoarthritis [40], these analyses principally focused on analyzing the effects of subgroups by clinical criteria such as BMI, baseline disease severity, etc. Alternatively, IPD meta-analyses were also used to better predict the efficacy of a CAM treatment for which multiple - inconclusive - single trials were available [41-43]. Only 1 IPD meta-analysis was identified which explicitly investigated the treatment modifying effect of some of the more specific characteristics of acupuncture treatment [44].

This study confirmed that IPD meta-analysis can be used to quantitatively investigate aspects of treatment individualization.

The main approach for quantitatively validating the role of homeopathic symptoms remains prognostic factor research in routine clinical practice. The role of clinical trials is likely to be limited for both methodological (such as lack of power and of external validity) and practical (such as cost) reasons. So, while it may not be necessary, or feasible, to set up clinical trials specifically for prognostic factor research purposes, it is possible to "piggyback" prognostic factor research on existing trials as a secondary objective for little extra cost. Recording the presence or absence of selected potential prognostic factors at baseline should therefore be considered in all trials of traditional and CAM treatment modalities with strong roots in treatment individualization.

This study illustrates that it is possible to quantitatively investigate aspects of treatment individualization alongside randomized trials. It was found that symptom amelioration by local heat is of possible value as a homeopathic symptom (prognostic factor) predicting an increased likelihood of pain relief following treatment with Spiroflor SRL gel.

\section{Acknowledgement}

The author gratefully acknowledges the contribution of Karel G. Moons, Prof. of Clinical Epidemiology, who contributed to the design, analysis, and reporting of this study. The author thanks Prof. Miek Jong for her valuable contributions to the analysis and reporting in this paper. The author also thanks Sytze de Roock for preparation of the tables and figures and Lex Rutten for his comments on earlier drafts of this paper. 


\section{Statement of Ethics}

The author has no ethical conflicts to disclose.

\section{Funding Sources}

This study was financially supported by VSM and the DHU.

\section{Conflict of Interest Statement}

The author was an employee of VSM bv from 1990 to 1995. The author received a consulting fee from VSM for the conduction of this study and from the DHU (German sister company of VSM) for writing this paper.

\section{Author Contributions}

R. van Haselen was responsible for planning and conduction of the 3 trials and involved in the planning, analysis, and writing of this individual patient data meta-analysis.

\section{References}

1 Clarke AM, Symmons DP. The burden of rheumatic disease. Medicine (Baltimore). 2006;34(9):333-5.

2 Vos T, Abajobir AA, Abate KH, Abbafati C, Abbas KM, Abd-Allah F, et al.: Global, regional, and national incidence, prevalence, and years lived with disability for 328 diseases and injuries for 195 countries, 1990-2016: a systematic analysis for the Global Burden of Disease Study 2016. Lancet. 2017 Sep;390: 1211-59.

3 European Committee for Homeopathy. LMHI and ECH Harmonized Homeopathic Proving Guidelines. 2017 [cited 2017 Sep]. Available from: https://homeopathyeurope. org/about/subcommittees/provings-subcommittee/.

4 Kent JT. Repertory of the homeopathic materia medica. 6th ed. New Delhi: Jain; 2004

5 Hahnemann S. Organon of medicine: the first integral English translation of the definitive sixth edition of the original work on homoeopathic medicine - translated by J. Kuenzli, MD, Alain Naud, and P. Pendleton. Minimum Price Books; 1983.

$6 \mathrm{Hall} \mathrm{KH}$. Reviewing intuitive decision-making and uncertainty: the implications for medical education. Med Educ. 2002 Mar; 36(3):216-24

7 Thompson TD. Can the caged bird sing? Reflections on the application of qualitative research methods to case study design in homeopathic medicine. BMC Med Res Methodol. 2004 Feb;4(1):4.

8 van Haselen R. Improving the efficacy of diagnosis in homoeopathy: towards a new methodology. Nijmegen: Faculty of Medicine; 1990. p. 36.

9 van Haselen R: Improving the efficacy of diagnosis in homeopathy: towards a new methodology. Homint R\&D Newsletter; 1990.

10 Deeks JJ, Altman DG. Diagnostic tests 4: likelihood ratios. BMJ. 2004 Jul;329(7458):168-9.

11 Stolper CF, Rutten AL, Lugten RF, Barthels RJ. Improving homeopathic prescribing by applying epidemiological techniques: the role of likelihood ratio. Homeopathy. 2002 Oct; 91(4):230-8.

12 Rutten AL, Stolper CF, Lugten RF, Barthels RW. Statistical analysis of six repertory rubrics after prospective assessment applying Bayes' theorem. Homeopathy. 2009 Jan; 98(1):26-34.
13 Rutten AL, Stolper CF, Lugten RF, Barthels RW. New repertory, new considerations. Ho meopathy. 2008 Jan;97(1):16-21.

14 Rutten AL, Stolper CF, Lugten RF, Barthels RW. Repertory and the symptom loquacity: some results from a pilot study on likelihood ratio. Homeopathy. 2004 Oct;93(4): 190-2.

15 Rutten AL, Stolper CF, Lugten RF, Barthels RW. Is assessment of likelihood ratio of homeopathic symptoms possible? A pilot study. Homeopathy. 2003 Oct;92(4):213-6.

16 Rutten AL, Stolper CF, Lugten RF, Barthels RW. Assessing likelihood ratio of clinical symptoms: handling vagueness. Homeopathy. 2003 Oct;92(4):182-6.

17 Runhaar J, Rozendaal RM, van Middelkoop M, Bijlsma HJ, Doherty M, Dziedzic KS, et al. Subgroup analyses of the effectiveness of oral glucosamine for knee and hip osteoarthritis: a systematic review and individual patient data meta-analysis from the OA trial bank. Ann Rheum Dis. 2017 Nov;76(11): 1862-9.

18 Moons KG, Altman DG, Reitsma JB, Ioannidis JP, Macaskill P, Steyerberg EW, et al. Transparent Reporting of a multivariable prediction model for Individual Prognosis or Diagnosis (TRIPOD): explanation and elaboration. Ann Intern Med. 2015 Jan;162(1):W173.

19 Thompson SG, Higgins JP. Treating individuals 4: can meta-analysis help target interventions at individuals most likely to benefit? Lancet. 2005 Jan;365(9456):341-6.

20 Moons KG, Royston P, Vergouwe Y, Grobbee DE, Altman DG. Prognosis and prognostic research: what, why, and how? BMJ. 2009 Feb; 338:b375.

21 Berlin JA, Santanna J, Schmid CH, Szczech LA, Feldman HI; Anti-Lymphocyte Antibody Induction Therapy Study Group. Individual patient- versus group-level data meta-regressions for the investigation of treatment effect modifiers: ecological bias rears its ugly head. Stat Med. 2002 Feb;21(3):37187.

22 Lambert PC, Sutton AJ, Abrams KR, Jones DR. A comparison of summary patient-level covariates in meta-regression with individual patient data meta-analysis. J Clin Epidemiol. 2002 Jan;55(1):86-94

23 Moons KG, Altman DG, Reitsma JB, Collins GS; Transparent Reporting of a Multivari- ate Prediction Model for Individual Prognosis or Development Initiative. New guideline for the reporting of studies developing, validating, or updating a multivariable clinical prediction model: the TRIPOD statement. Adv Anat Pathol. 2015 Sep; 22(5):303-5.

24 Heemsbergen W. The efficacy of SRL gel in symptomatic, primary osteoarthritis of the knee. Clinical Study Report P9126, 1999.

25 Stam C, Bonnet MS, van Haselen RA. The efficacy and safety of a homeopathic gel in the treatment of acute low back pain: a multi-centre, randomised, double-blind comparative clinical trial. Br Homeopath J. 2001 Jan;90(1): 21-8.

26 van Haselen RA, Fisher PA. A randomized controlled trial comparing topical piroxicam gel with a homeopathic gel in osteoarthritis of the knee. Rheumatology (Oxford). $2000 \mathrm{Jul}$ 39(7):714-9.

27 Huskisson EC. Measurement of pain. Lancet. 1974 Nov;2(7889):1127-31

28 Fisher P, Greenwood A, Huskisson EC, Turner P, Belon P. Effect of homeopathic treatment on fibrositis (primary fibromyalgia) BMJ. 1989 Aug;299(6695):365-6.

29 Vickers AJ, Altman DG: Statistics notes: analysing controlled trials with baseline and follow up measurements. BMJ. 2001 Nov 10; 323(7321):1123-4.

30 Johnston SC. Combining ecological and individual variables to reduce confounding by indication: case study-subarachnoid hemorrhage treatment. J Clin Epidemiol. 2000 Dec; 53(12):1236-41.

31 Yamamoto LG, Nomura JT, Sato RL, Ahern RM, Snow JL, Kuwaye TT. Minimum clinically significant VAS differences for simultaneous (paired) interval serial pain assessments. Am J Emerg Med. 2003 May;21(3): 176-9.

32 Frei H. Polarity analysis, a new approach to increase the precision of homeopathic prescriptions. Homeopathy. 2009 Jan;98(1):4955.

33 Weingärtner O. Homeopathic combination preparations; origin, development and selfconception. Essen: KVC; 2007.

34 Rawat P. Select your dose and potency. New Delhi: Jain; 1988.

35 Geneper TH, Wegener A: Lehrbuch der Homoopathie: Grundlagen und Praxis. Heidelberg: Haug; 2001 
36 Jacobs J, Guthrie BL, Montes GA, Jacobs LE, Mickey-Colman N, Wilson AR, et al. Homeopathic combination remedy in the treatment of acute childhood diarrhea in Honduras. J Altern Complement Med. 2006 Oct;12(8): 723-32.

37 Jacobs J, Jiménez LM, Gloyd SS, Gale JL, Crothers D. Treatment of acute childhood diarrhea with homeopathic medicine: a randomized clinical trial in Nicaragua. Pediatrics. 1994 May;93(5):719-25.

38 Jacobs J, Jiménez LM, Malthouse S, Chapman E, Crothers D, Masuk M, et al. Homeopathic treatment of acute childhood diarrhea: results from a clinical trial in Nepal. J Altern Complement Med. 2000 Apr;6(2):131-9.
39 Jacobs J, Jonas WB, Jiménez-Pérez M, Crothers D. Homeopathy for childhood diarrhea: combined results and metaanalysis from three randomized, controlled clinical trials. Pediatr Infect Dis J. 2003 Mar;22(3):229-34.

40 Zheng $\mathrm{Q}$, Zheng H, Lu L, Leng J, Zhou S, Zheng $\mathrm{H}$, et al. Acupuncture for functional constipation: protocol of an individual patient data meta-analysis. BMJ Open. 2015 May;5(5):e007137.

41 Yan SY, He LY, Liu BY. Individual patient data meta-analysis is needed in Chinese medical research. Chin J Integr Med. 2014 Nov; 20(11):805-11.
42 Ziegler R, Grossarth-Maticek R. Individual patient data meta-analysis of survival and psychosomatic self-regulation from published prospective controlled cohort studies for long-term therapy of breast cancer patients with a mistletoe preparation (iscador). Evid Based Complement Alternat Med. 2010 Jun;7(2):157-66.

43 Abo-Zaid G, Sauerbrei W, Riley RD. Individual participant data meta-analysis of prognostic factor studies: state of the art? BMC Med Res Methodol. 2012 Apr;12(1):56.

44 Collins GS, Reitsma JB, Altman DG, Moons KG. Transparent reporting of a multivariable prediction model for individual prognosis or diagnosis (TRIPOD): the TRIPOD statement. BMJ. 2015 Jan;350:g7594. 
